\title{
Amniotic Fluid Embolism: A Case Study and Literature Review
}

\section{Ryan J Elsey DO ${ }^{1^{*}}$, Mary K Moats-Biechler OMS-IV², Michael W Faust MD ${ }^{3}$, Jennifer A Cooley CRNA-APRN ${ }^{4}$, Sheela Ahari MD', and Douglas T Summerfield $M D^{1}$}

Departments of Internal Medicine ${ }^{1}$, Obstetrics and Gynecology ${ }^{3}$, and Anesthesia ${ }^{4}$ Mercy Medical Center-North lowa Mason City, IA USA

${ }^{2}$ A.T. Still University Kirksville, MO USA

\begin{abstract}
Amniotic fluid embolus is a rare and life threatening peripartum complication that requires quick recognition and emergent interdisciplinary management to provide the best chance of a positive outcome for the mother and infant. The following case study demonstrates the importance of quick recognition as well as an interdisciplinary approach in caring for such a condition. A literature review regarding the current recommendations for management of this condition follows as well as a proposed treatment algorithm.
\end{abstract}

\section{Introduction}

Amniotic fluid embolus (AFE) is a rare and life-threatening complication of pregnancy; a recent population-based review found an estimated incidence ranging from 1 in 15,200 deliveries in North America and 1 in 53,800 deliveries in Europe (1). Mortality rates vary but have been reported to range from $11 \%$ to more than $60 \%$, with the most recent population-based studies in the United States reporting a $21.6 \%$ fatality rate (1-4). Despite best efforts, it remains one of the leading causes of maternal death $(1,5,6)$. However, rapid diagnosis of AFE and immediate obstetric and intensive care has proven to play a decisive role in maternal prognosis and survival (7-9).

In 2016, uniform diagnostic criteria were proposed for reporting on cases of AFE. First, a report of AFE requires a sudden onset of cardiorespiratory arrest, which consists of both hypotension (systolic blood pressure $<90 \mathrm{mmHg}$ ) and respiratory compromise (dyspnea, cyanosis, or SpO2 < 90\%). Secondly, overt disseminated intravascular coagulation (DIC) must be documented following the appearance of signs or symptoms using a standardized scoring system. Coagulopathy must be detected prior to a loss of sufficient blood to account for dilutional or shock-related consumptive coagulopathy. Third, the clinical onset must occur during labor or within 30 minutes of delivery of the placenta. Fourth, no fever $\geq 38.0^{\circ} \mathrm{C}$ during labor can occur (10).

The following case study qualifies as a reportable incidence of an AFE under the above criteria and further demonstrates the ability to successfully stabilize a patient with AFE 
due to quick recognition, interdisciplinary cooperation, and effective supportive management.

\section{Case Presentation}

A 34-year-old gravida 5, para 1-1-2-2, presented at 36 weeks and 1-day gestation for induction of labor. Her past medical history included esophageal atresia at birth and a past pregnancy complicated by preterm, premature rupture of the membranes. Initial labs at admission were significant for a hemoglobin of $12.2 \mathrm{~g} / \mathrm{dL}$ and a platelet count of $234 \times 10^{3} \mathrm{u} / \mathrm{L}$. The patient was subsequently started on lactated ringers at $125 \mathrm{ml} / \mathrm{hr}$. As the patient's labor progressed, an epidural was placed 3 hours after admission. Four hours and 42 minutes after admission, an artificial rupture of the membranes was performed.

Eighteen minutes after the artificial rupture of the membranes was performed, the patient was noted to have seizure-like activity. She was given an intravenous (IV) fluid bolus and ephedrine, and the anesthesia provider was emergently contacted. When anesthesia arrived, the patient was noted to be cyanotic in bed. Patient vitals and exam were significant for emesis, a heart rate of 50 beats per minute (bpm), systolic blood pressure in the low $70 \mathrm{~s}(\mathrm{mmHg})$, and a fetal heart rate in the $70 \mathrm{~s}$.

The differential diagnosis at this time was broad and included anesthesia drug reactions such as an intravascular epidural migration, pulmonary thromboembolism, eclampsia, or even an aortic dissection. A pulmonary embolism was felt to be unlikely due to the patient's bradycardia and sudden neurologic changes. Eclampsia was less likely at the time due to no signs of pre-eclampsia in the patient as well as the patient's current bradycardia and hypotension. Given the patient's absence of Marfan syndrome, aortic dissection was not considered to be a high probability. The patient did have signs consistent with an intravascular epidural including altered mental status, cyanosis, bradycardia, hypotension, vomiting, and a low fetal heart rate. However, at the time anesthesia felt she was more likely suffering from an acute embolic process given the timeframe between the artificial rupture of the membranes and the onset of her symptoms.

Given the patient's instability, she was emergently taken for a cesarean section and intubated to provide airway stabilization. The cesarean section began 15 minutes after seizure like symptoms started and upon delivery, the infant was subsequently transferred to a tertiary center for therapeutic hypothermia.

Intraoperatively, the patient was noted to maintain a peripheral capillary oxygen saturation (SpO2) of $>90 \%$. However, end tidal C02 was elevated to $54 \mathrm{mmHg}$ despite hyperventilation and peak airway pressures were elevated to $38 \mathrm{cmH}_{2} \mathrm{O}$. Albuterol and sevoflurane were subsequently utilized in an attempt to increase bronchodilation. Following completion of the caesarian section, peak airway pressures normalized to less than $30 \mathrm{cmH}_{2} \mathrm{O}$ but end tidal CO2 levels remained as high as $52 \mathrm{mmHg}$ despite 
hyperventilation. Blood pressure was significant for systolic pressure of $80 \mathrm{mmHg}$. IV phenylephrine was administered. Additionally, uterine massage was performed to aid in hemorrhage control and the patient was administered IV oxytocin, methylergonovine maleate, carboprost, and vaginal misoprostol. A repeat complete blood count was performed one hour after symptom onset which showed a hemoglobin of $10.3 \mathrm{~g} / \mathrm{dL}$ and a platelet count of $103 \times 10^{3} \mathrm{u} / \mathrm{L}$.

In this case, the patient's care team had a high suspicion of an AFE with symptoms that followed the uniform diagnostic criteria for an AFE. The patient had hemodynamic instability, coinciding with the recent rupture of membranes. Her systolic blood pressure was $<90 \mathrm{mmHg}$ and her end tidal C02 levels (in $\mathrm{mmHg}$ ) were elevated to the high 40s and low 50s. The critical care team was notified of her condition and the patient was subsequently transferred to the Intensive Care Unit (ICU) on mechanical ventilation and sedated with fentanyl and versed.

Upon arrival to the ICU, a DIC panel was performed revealing DIC. Labs showed a fibrinogen level of $52 \mathrm{mg} / \mathrm{dL}$, A D-dimer greater than $128,000 \mathrm{ng} / \mathrm{mL}$, and a platelet count of $80,000 \mathrm{u} / \mathrm{L}$ despite the administration of one pooled unit of platelets. The patient's international normalized ratio (INR) was 1.3 with a baseline INR of 0.9. Due to multiple laboratory abnormalities and a clinical condition consistent with DIC, aggressive transfusions were performed per the standard of care for patients suffering with DIC. A peripheral smear was obtained revealing schistocytes (Figure 1) which verified the DIC diagnosis.

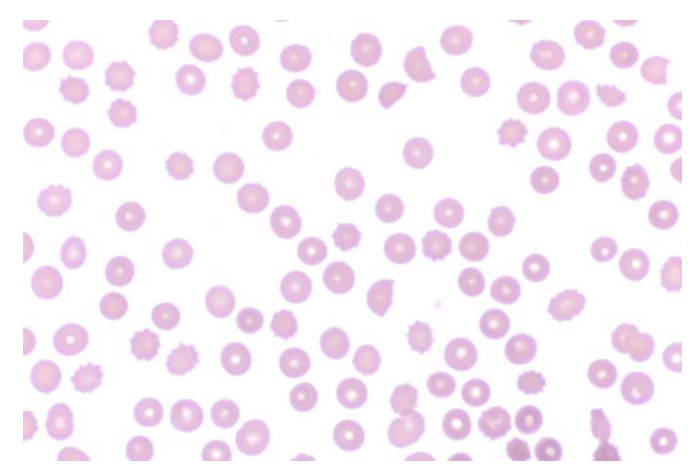

Figure 1. The patient's peripheral blood smear four hours after onset of symptoms which demonstrates schistocytes indicative of DIC.

Hematology was emergently consulted and it was recommended to avoid additional platelet transfusions unless platelet counts dropped below 10,000 to 20,000 u/L. One milligram $(\mathrm{mg})$ of subcutaneous phytonadione was also given five hours after symptom onset in an effort to decrease bleeding.

Cardiology was consulted and performed an emergent echocardiogram to assess the patient's heart function and rule out any cardiac abnormalities. Given her past history of esophageal atresia, there was particular concern about an underlying ventricular septal 
defect, patent ductus arteriosus, or tetralogy of Fallot (11). The echocardiogram revealed a dilated, yet functional right ventricle, which was expected in the setting of an AFE. ICU physicians at a tertiary care center were provisionally consulted to confirm that the patient was a candidate for arteriovenous extracorporeal membrane oxygenation (AV-ECMO) should she suffer further cardiopulmonary collapse. Labs, including hemoglobin, platelets, fibrinogen activity, and ionized calcium were drawn every two hours during the acute phase of the patient's management and abnormalities were addressed as required over the subsequent two hours. The patient's hemoglobin was noted to decline to as low as $6.7 \mathrm{~g} / \mathrm{dL}$. Of note, lab draws did suffer some sample lysis due to the patient's coagulation abnormalities. The patient did initially require phenylephrine for blood pressure support. Additionally, she was placed on an experimental septic shock protocol which involved the administration of $1500 \mathrm{mg}$ of ascorbic acid every six hours, $60 \mathrm{mg}$ of methylprednisolone every six hours, and 200 $\mathrm{mg}$ of thiamine every 12 hours. The patient began to stabilize around 10 to 12 hours after her AFE symptoms began and pressor support was titrated off, at which point blood draws were liberalized to every four hours. The patient continued to improve and remained stable overnight.

On hospital day two, the patient was noted to be alert and was successfully extubated. Following extubation, the physical exam found her to be neurologically and hemodynamically intact. During her stay in the ICU, the patient received a total of eight units of packed red blood cells, five units of fresh frozen plasma, one pooled unit of platelets, and one unit of cryoprecipitate. The patient was ultimately discharged from the hospital on day four with no long-term sequelae noted.

The patient was informed that data from the case would be submitted for publication and gave her consent.

\section{A Review of the Literature}

AFE remains one of the leading causes of direct, maternal mortality among developed countries $(1,12,13)$. Multiple reviews have studied the incidence of AFE varies widely, from 1.9 per 100,000 to 7.7 per 100,000 pregnancies, with the reported fatality rate due to AFE ranging from $11 \%$ to more than $60 \%$, depending on the study $(1,2,4,14)$. The difficulty in reporting an accurate incidence and fatality rate is likely secondary to the fact that AFE remains a diagnosis of exclusion. AFE is traditionally diagnosed clinically during labor in a woman with ruptured membranes and a triad of symptoms, including unexplained cardiovascular collapse, respiratory distress, and DIC. (1,2,15-18). Additional symptoms may include hypotension, frothing from the mouth, fetal heart rate abnormalities, loss of consciousness, bleeding, uterine atony, and seizure-like activity $(15,16,19)$.

The majority of women who fail to survive an AFE die during the acute phase (median of one hour and 42 minutes after presentation) $(2,6)$. Surviving beyond the acute phase dramatically improves their overall chance of survival; however, survival is not without 
long term morbidities. Analysis performed in the United Kingdom in 2005 and again in 2015 showed that $7 \%$ of woman surviving AFE have permanent neurological injury, including persistent vegetative state/anoxic/hypoxic brain injury or cerebrovascular accident $(2,7)$. Among survivors, $17 \%$ were shown to have other comorbidities, including sepsis, renal failure, thrombosis or pulmonary edema and $21 \%$ required a hysterectomy $(2,6)$.

Despite several decades of research, the pathogenesis of an AFE continues to remain somewhat clouded. Multiple theories have been postulated concerning the clinical manifestations occurring with an AFE and their relationship with the passage of amniotic fluid into the systemic maternal circulation. The first theory proposed described amniotic debris passing through the veins of the endocervix and into maternal circulation, resulting in an obstruction $(1,6)$. This theory has fallen out of favor as there is no physical evidence of obstruction noted on radiologic studies, autopsies, or experimentally in animal models $(1,20,21)$. Additionally, multiple studies have found that that the passage of amniotic and fetal cells into maternal circulation are very common during pregnancy and delivery (6). Thus, most theories today focus on humoral and immunological factors and how they affect the body $(5,22,23)$. Current research focuses on the effect of amniotic fluid on the body after it has already entered into maternal circulation. It is theorized that the amniotic fluid results in the release of various endogenous mediators, resulting in the physiologic changes that are seen with an AFE. Proposed mediators include histamine (22), bradykinin (24), endothelin $(25,26)$, leukotrienes (27), and arachidonic acid metabolites (28).

The hemodynamic response to AFE is biphasic in nature. It consists of vasospasm, resulting in severe pulmonary hypertension, and intense vasoconstriction of the pulmonary vasculature secondary to the amniotic fluid itself, which can lead to ventilation-perfusion mismatch and resultant hypoxia $(5,6,29)$. On an echocardiogram, the initial phase of an AFE consists of right ventricular failure demonstrated by a severely dilated, hypokinetic right ventricle with deviation of the interventricular septum into the left ventricle (18). Following the initial phase of right ventricular failure, which can lasts minutes to hours, left ventricular failure along with cardiogenic, pulmonary edema becomes the prominent finding $(1,5)$. This occurs due to a reduction in preload as well as systemic hypotension. These changes may decrease coronary artery perfusion, which can result in myocardial injury, precipitation of cardiogenic shock, and worsening of distributive shock $(1,6,30)$.

$\mathrm{DIC}$ is present in up to $83 \%$ of patients experiencing an AFE; however, its onset during presentation can be variable (31). It may present within the first ten minutes following cardiovascular collapse, or it may precipitate up to nine hours following the initial clinical manifestation $(5,31,32)$. The precipitating pathophysiology behind DIC in AFE is poorly understood, but is likely to be consumptive, rather than fibrinolytic, in nature. In an AFE it is currently theorized that tissue factor, which is present in amniotic fluid, activates the extrinsic pathway by binding with factor VII, triggering clotting to occur by activating factor $X$, resulting in the consumptive coagulopathy $(1,33-35)$. Ultimately, it is felt that 
this coagulation leads to vasoconstriction of the microvasculature and thrombosis by producing thrombin that is secreted into the endothelin, leading to the changes seen in DIC $(1,5,6,14,18)$.

\section{Recommended Management for AFE Based on Current Literature}

Early recognition of AFE and immediate obstetric and intensive care has proven to play a decisive role in maternal prognosis and survival $(7,8)$. In order to survive an AFE, patients require immediate multidisciplinary management with a focus on maintaining oxygenation, circulatory support, and correcting coagulopathy $(1,6)$.

A literature review of the current management for patients presenting with AFE recommends standard initial lifesaving supportive care. This should begin with immediate protection of the patient's airway via endotracheal intubation and early, sufficient oxygenation using an optimized positive end-expiratory pressure (FiO2:PEEP) ratio, which also decreases the risk of aspiration $(1,5,29)$. Two large bore IV lines should be placed for crystalloid fluid resuscitation. In the setting of a cardiopulmonary arrest, cardiopulmonary resuscitation should be initiated and an immediate caesarian section within three to five minutes should be performed in the presence of a fetus $\geq 23$ weeks gestation $(5,18,36-38)$. This serves several purposes, including decreasing the risk of the infant suffering from long term neurologic injury secondary to hypoxia, improving venous flow to the right heart by emptying the uterus, and reducing pressure on the inferior vena cava to decrease impedance to blood flow, which decreases systemic blood pressure $(1,5,31,39,40)$.

During the initial phase, attention should be paid to avoid hypoxia, acidosis, and hypercapnia due to their ability to increase pulmonary vascular resistance and lead to worsening of right heart failure and recommendations include sildenafil, inhaled or injected prostacyclin, and inhaled nitric oxide (6). Recommendations to treat for hypotension during this phase include the utilization of vasopressors, such as norepinephrine or vasopressin $(1,6,18,37,41)$. Hemodynamic management during the second phase should focus on the patient's left-sided heart failure by optimizing cardiac preload via vasopressors to maintain perfusion and utilizing inotropes such as dobutamine or milrinone to increase left ventricular contractility $(1,6,18)$.

Due to the relationship between AFE and DIC, current recommendations suggest early assessment of the patient's coagulation status. Additionally, in the setting of a massive hemorrhage, blood product administration should not be delayed while awaiting laboratory results (18). Early corrective management of the patient's coagulopathy should be aggressive in nature, especially in the setting of a massive hemorrhage. Tranexamic acid and fibrinogen concentrate (for fibrinogen levels below $2 \mathrm{~g} / \mathrm{L}$ ) are essential in the treatment of hyper-fibrinolysis. Additionally, multiple obstetric case studies have shown fibrinogen replacement to benefit from bedside rotational thromboelastometry if available due to its ability to rapidly diagnosis consumptive versus fibrinolytic coagulopathy at the bedside $(5,42,43)$. Hemostatic resuscitation with 
packed red blood cells, fresh-frozen plasma, and platelets at a ratio of 1:1:1 should be administered $(6,18)$. Cryoprecipitate replacement is recommended as well due to the consumptive nature of DIC in AFE, and its importance should not be understated. A 2015 population-based cohort study showed that women with AFE who died or had permanent neurologic injury were less likely to have received cryoprecipitate than those who survived and were without permanent neurologic injury $(1,2)$. Furthermore, due to the dynamic processes of chemodynamical labs, including hemoglobin, platelet count, and fibrinogen must be monitored closely to prevent complications or over transfusion (14).

Uterine atony is a common feature with AFE and it is recommended to immediately administer uterotonics during the postpartum period to prevent its occurrence $(5,44)$. Should it occur, uterine atony should be managed aggressively via uterotonics such as oxytocin, ergot derivatives, and prostaglandins; refractory cases may require packing material for uterine tamponade, uterine artery ligation, or even a hysterectomy for the most severe $(5,8,18)$.

In addition to the treatments listed above, multiple case reports support the use of aggressive or novel therapeutic modalities to aid in the treatment of AFE; however, for many of the treatments, evidence supporting increased survival of an AFE is merely anecdotal (18). Among the best supported ancillary treatments is nonarterial extracorporeal membrane oxygenation as a possible therapeutic treatment for patients with refractory acute respiratory distress syndrome. However, due to the profoundly coagulopathic state of AFE and the active hemorrhage occurring with AFE, the use of anticoagulation may profoundly worsen bleeding. Consequently, extracorporeal membrane oxygenation is controversial and not routinely recommended in the management of AFE $(6,18)$. Similarly, post-cardiac arrest therapeutic hypothermia with a range of $32^{\circ} \mathrm{C}$ to $34^{\circ} \mathrm{C}$ is often avoided in patients with AFE due to the increased risk of hemorrhage given their predisposition for DIC (18). However, in patients not demonstrating DIC and overt bleeding, targeted temperature management to $36^{\circ} \mathrm{C}$ and preventing hyperthermia is an option that should be considered $(17,45,46)$. Factor VIla procoagulant, which increases thrombin formation, has been utilized anecdotally, but strong supporting data is lacking; it should only be considered if following the replacement with massive coagulation factors, hemostasis and bleeding fail to improve $(5,47)$. Additionally, it is important to note that factor VIla replacement is only effective if other clotting factors have been replaced $(1,6,48,49)$. Novel therapeutic modalities mentioned in the literature also include continuous hemofiltration, cardiopulmonary bypass, nitric oxide, steroids, $\mathrm{C} 1$ esterase inhibitor concentrate, and plasma exchange transfusion. While there are case reports published to suggest that all of the aforementioned therapies may provide some level of improvement in patients with AFE, the positive results from these cases may be due to their administration during the intermediate phase of AFE as opposed to the acute phase of AFE, where the majority of mortality occurs-once patients have surpassed the early, acute phase, survival chances greatly improve with continued supportive care $(1,6)$. 
AFE has traditionally been viewed as a condition associated with poor outcomes and a high mortality rate for both the mother and the infant. However, with quick AFE recognition, high quality supportive care, and interdisciplinary cooperation, patients can have positive outcomes. Based on the success with the patient presented in this case and the review of the current literature as seen above, the authors have proposed an algorithm (Figure 2) for the treatment of future patients experiencing AFE.

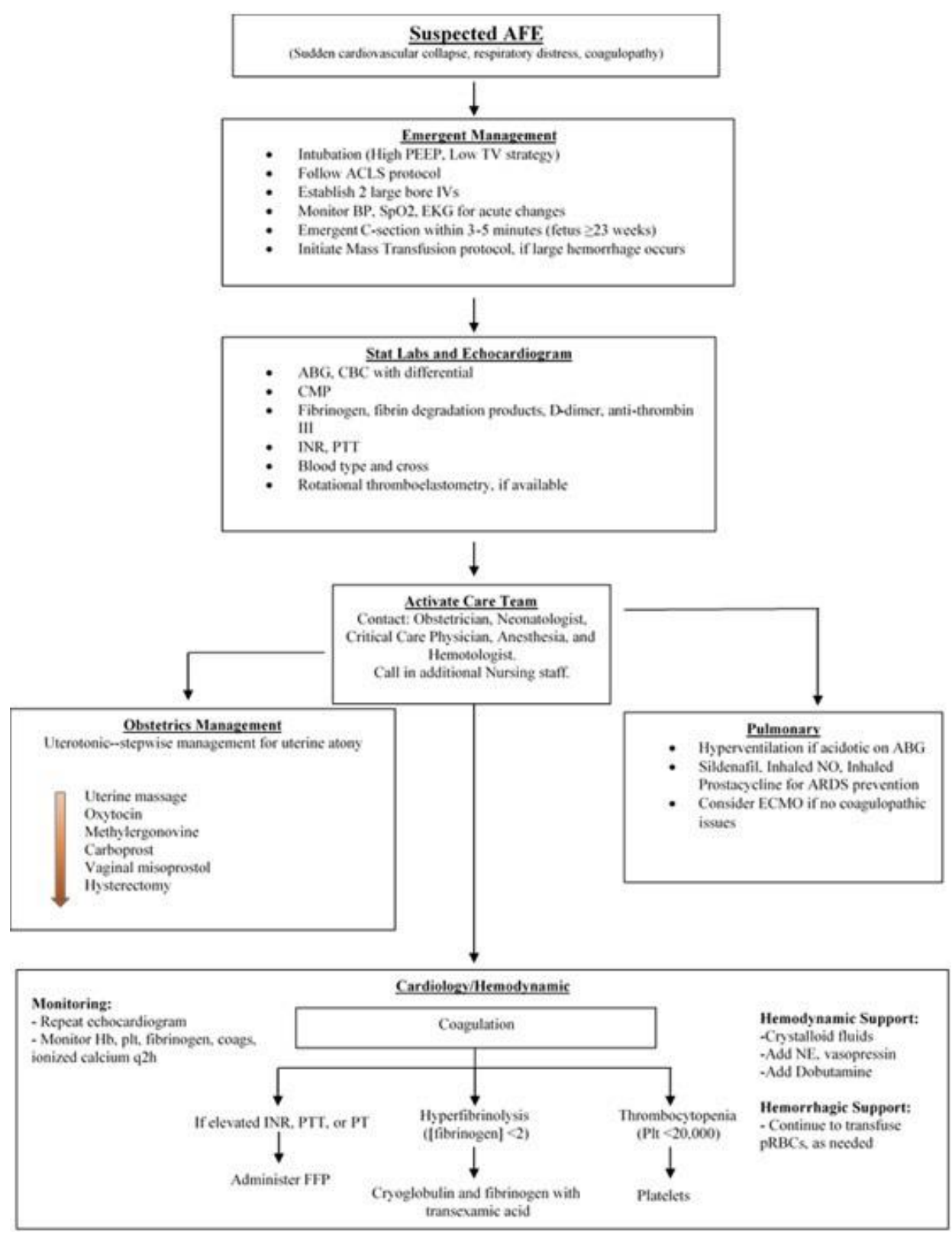

Figure 2. Proposed interdisciplinary treatment algorithm for acute management of an AFE.

By following the algorithm, the authors believe that the outcomes for AFE patients can be improved. 


\section{Abbreviations}

PEEP: positive end-expiratory pressure; BP: blood pressure; TV: tidal volume; ACLS: Advanced cardiac life support; ABG: Arterial blood gas; CBC: Complete blood count; CMP: Complete metabolic profile; INR: International normalized ratio; PTT: Partial prothrombin time; ART line: Arterial line; NO: Nitric oxide; ARDS: Acute respiratory distress syndrome; ECMO:

Extracorporeal membrane oxygenation; FFP: Fresh frozen plasma; Plt: Platelet; pRBCs: Packed red blood cells; NE: Norepinephrine.

\section{References}

1. Conde-Agudelo A, Romero R. Amniotic fluid embolism: an evidence-based review. Am J Obstet Gynecol. 2009;201(5):445-e1. [CrossRef] [PubMed]

2. Fitzpatrick D, Tuffnell D, Kurinczuk J, Knight M. Incidence, risk factors, management and outcomes of amniotic-fluid embolism: a population-based cohort and nested case-control study. BJOG. 2016 Jan;123(1):100-9. [CrossRef] [PubMed]

3. Cunningham FG, Nelson BD. Disseminated intravascular coagulation syndromes in obstetrics. Obstet Gynecol. 2015;126(5):999-1011. [CrossRef] [PubMed]

4. Knight $M$, Berg $C$, Brocklehurst $P$, et al. Amniotic fluid embolism incidence, risk factors and outcomes: a review and recommendations. BMC Pregnancy Childbirth. 2012 Feb 10;12:7. [CrossRef] [PubMed]

5. Rath WH, Hofer S, Sinicina I. Amniotic fluid embolism: an interdisciplinary challenge: epidemiology, diagnosis and treatment. Deutsches Ärzteblatt International. 2014;111(8):126. [CrossRef] [PubMed]

6. Tuffnell DJ, Slemeck E. Amniotic fluid embolism. Obstetrics,Gynaecology \& Reproductive Medicine. 2017;27(3):86-90. [CrossRef]

7. Tuffnell D. United Kingdom amniotic fluid embolism register. BJOG. 2005;112(12):1625-9. [CrossRef] [PubMed]

8. Matsuda Y, Kamitomo M. Amniotic fluid embolism: a comparison between patients who survived and those who died. J Int Med Res. 2009;37(5):1515-1521. [CrossRef] [PubMed]

9. $\mathrm{CEMACH}$. Confidential enquiry into maternal deaths in the United Kingdom,why mothers die 2000-2002. Royal College of Obstetricians and Gynaecologists. 2004.

10. Clark SL, Romero R, Dildy GA, et al. Proposed diagnostic criteria for the case definition of amniotic fluid embolism in research studies. Am J Obstet Gynecol. 2016;215(4):408-12. [CrossRef] [PubMed]

11. Clark DC. Esophageal atresia and tracheoesophageal fistula. Am Fam Physician. 1999;59(4):910-916,919-20. [PubMed]

12. Berg CJ, Callaghan WM, Syverson C, Henderson Z. Pregnancy-related mortality in the United States, 1998 to 2005. Obstet Gynecol. 2010;116(6):1302-9. [CrossRef] [PubMed]

13. Cantwell R, Clutton-Brock T, Cooper G, et al. Saving Mothers' Lives: Reviewing maternal deaths to make motherhood safer: 2006-2008. The Eighth Report of the Confidential Enquiries into Maternal Deaths in the United Kingdom. BJOG. 2011;118 Suppl 1:1-203. [CrossRef] [PubMed] 
14. Erez O, Mastrolia SA, Thachil J. Disseminated intravascular coagulation in pregnancy: insights in pathophysiology, diagnosis and management. Am J Obstet Gynecol. 2015;213(4):452-63. [CrossRef] [PubMed]

15. Rezai S, Hughes AC, Larsen TB, Fuller PN, Henderson CE. Atypical amniotic fluid embolism managed with a novel therapeutic regimen. Case Rep Obstet Gynecol. 2017;2017:8458375. [CrossRef] [PubMed]

16. Clark SL. Amniotic fluid embolism. Obstet Gynecol. 2014;123(2 Pt 1):337-48. [CrossRef] [PubMed]

17. Clark SL, Montz FJ, Phelan JP. Hemodynamic alterations associated with amniotic fluid embolism: a reappraisal. Am J Obstet Gynecol. 1985;151(5):617-21. [CrossRef] [PubMed]

18. Pacheco LD, Saade G, Hankins GD, Clark SL. Amniotic fluid embolism: diagnosis and management. Am J Obstet Gynecol. 2016;215(2):B16-24. [CrossRef] [PubMed]

19. Clark SL. Amniotic fluid embolism. Clin Obstet Gynecol. 2010;53(2):322-8. [CrossRef] [PubMed]

20. Stolte L, van Kessel H, Seelen J, Eskes T, Wagatsuma T. Failure to produce thesyndrome of amniotic fluid embolism by infusion of amniotic fluid and meconium into monkeys. Am J Obstet Gynecol. 1967;98(5):694-7. [CrossRef] [PubMed]

21. Adamsons K, Mueller-Heubach E, Myers RE. The innocuousness of amniotic fluid infusion in the pregnant rhesus monkey. Am J Obstet Gynecol. 1971;109(7):977-84. [CrossRef] [PubMed]

22. Benson MD. A hypothesis regarding complement activation and amniotic fluid embolism. Med Hypotheses. 2007;68(5):1019-25. [CrossRef] [PubMed]

23. Benson MD. Current concepts of immunology and diagnosis in amniotic fluid embolism. Clin Dev Immunol. 2012;2012:946576. [CrossRef] [PubMed]

24. Robillard J, Gauvin F, Molinaro G, Leduc L, Adam Arrived GE. The syndrome of amniotic fluid embolism: a potential contribution of bradykinin. Am J Obstet Gynecol. 2005;193(4):1508-12. [CrossRef] [PubMed]

25. el Maradny Kandalama Halim A, Maehara K, Terao T. Endothelin has a role in early pathogenesis of amniotic fluid embolism. Gynecol Obstet Invest. 1995;40(1):14-8. [CrossRef] [PubMed]

26. Khong TY. Expression of endothelin-1 in amniotic fluid embolism and possible pathophysiological mechanism. BJOG. 1998;105(7):802-4. [CrossRef] [PubMed]

27. Azegami Memoria N. Amniotic fluid embolism and leukotrienes. Am J Obstet Gynecol. 1986;155(5):1119-24. [CrossRef] [PubMed]

28. Clark SL. Arachidonic acid metabolites and the pathophysiology of amniotic fluid embolism. Semin Reprod Endocrinol. 1985;3:253-7. [CrossRef]

29. Stafford I, Sheffield J. Amniotic fluid embolism. Obstet Gynecol Clin North Am. 2007;34(3):545-53,xii. [CrossRef] [PubMed]

30. Steiner PE, Lushbaugh CC, Frank HA. Fatal obstetric shock for pulmonary emboli of amniotic fluid. Am J Obstet Gynecol. 1949;58(4):802-5. [CrossRef] [PubMed]

31. Clark SL, Hankins GD, Dudley DA, Dildy GA, Porter TF. Amniotic fluid embolism: analysis of the national registry. Am J Obstet Gynecol. 1995;172(4 Pt 1):1158-67; discussion 1167-9. [CrossRef] [PubMed]

32. Dean LS, Rogers RP,3rd, Harley RA, Hood DD. Case scenario: amniotic fluid embolism. Anesthesiology. 2012;116(1):186-92. [CrossRef] [PubMed] 
33. Lockwood CJ, Bach R, Guha A, Zhou XD, Miller WA, Nemerson Y. Amniotic fluid contains tissue factor, a potent initiator of coagulation. Am J Obstet Gynecol.1991;165(5 Pt 1):1335-41. [CrossRef] [PubMed]

34. McDougall RJ, Duke GJ. Amniotic fluid embolism syndrome: case report and review. Anaesth Intensive Care. 1995;23(6):735-40. [CrossRef] [PubMed]

35. Uszynski M, Zekanowska E, Uszynski W, Kuczynski J. Tissue factor (TF) and tissue factor pathway inhibitor (TFPI) in amniotic fluid and blood plasma: implications for the mechanism of amniotic fluid embolism. Eur J Obstet Gynecol Reprod Biol. 2001;95(2):163-6. [CrossRef] [PubMed]

36. Jeejeebhoy FM, Zelop CM, Lipman S, et al. Cardiac Arrest in Pregnancy: A Scientific Statement from the American Heart Association. Circulation. 2015;132(18):1747-73. [CrossRef] [PubMed]

37. O'Shea A, Eappen S. Amniotic fluid embolism. Int Anesthesiol Clin. 2007;45(1):1728. [CrossRef] [PubMed]

38. Davies S. Amniotic fluid embolus: a review of the literature. Can J Anaesth. 2001;48(1):88-98. [CrossRef] [PubMed]

39. Martin RW. Amniotic fluid embolism. Clin Obstet Gynecol. 1996;39(1):101-6. [CrossRef] [PubMed]

40. Martin PS, Leaton MB. Emergency. Amniotic fluid embolism. Am J Nurs. 2001;101(3):43-44. [CrossRef] [PubMed]

41. Moore J, Baldisseri MR. Amniotic fluid embolism. Crit Care Med. 2005;33(10 Suppl):S279-285.[CrossRef] [PubMed]

42. Collins NF, Bloor M, McDonnell NJ. Hyperfibrinolysis diagnosed by rotational thromboelastometry in a case of suspected amniotic fluid embolism. Int $\mathrm{J}$ Obstet Anesth. 2013;22(1):71-6. [CrossRef] [PubMed]

43. Loughran JA, Kitchen TL, Sindhaker S, Ashraf M, Awad M, Kealaher EJ. Rotational thromboelastometry (ROTEM®)-guided diagnosis and management of amniotic fluid embolism. Int J Obstet Anesth. 2018. Sep 11. pii: S0959-289X(18)30122-5. [CrossRef] [PubMed]

44. Tuffnell D, Knight M, Plaat F. Amniotic fluid embolism - an update. Anaesthesia. 2011;66(1):3-6. [CrossRef] [PubMed]

45. Nielsen N, Wetterslev J, Cronberg T, et al. Targeted temperature management at 33 C versus 36 C after cardiac arrest. N Engl J Med. 2013;369(23):2197-206. [CrossRef] [PubMed]

46. Callaway CW, Donnino MW, Fink EL, et al. Part 8: Post-cardiac arrest care: 2015 American Heart Association Guidelines update for cardiopulmonary resuscitation and emergency cardiovascular care. Circulation. 2015;132(18 Suppl 2):S465-82. [CrossRef] [PubMed]

47. Leighton BL, Wall MH, Lockhart EM, Phillips LE, Zatta AJ. Use of recombinant factor VIla in patients with amniotic fluid embolism: a systematic review of case reports. Anesthesiology. 2011;115(6):1201-8. [CrossRef] [PubMed]

48. Prosper SC, Goudge CS, Lupo VR. Recombinant factor VIla after amniotic fluid embolism and disseminated intravascular coagulopathy. Obstet Gynecol. 2007;109(2 pt 2):524-5. [CrossRef] [PubMed] 
49. Lim Y, Loo CC, Chia V, Fun W. Recombinant factor VIla after amniotic fluid embolism and disseminated intravascular coagulopathy. Int J Gynaecol Obstet. 2004;87(2):178-9. [CrossRef] [PubMed] 